\title{
Global microRNA Expression Profiling of Buffalo (Bubalus Bubalis) Embryos at Different Developmental Stages Produced by Somatic Cell Nuclear Transfer and in Vitro Fertilization Using Rna Sequencing
}

Pallavi Goel ( $\sim$ pallavi.goel1091@gmail.com )

ICAR-National Dairy Research Institute (Deemed University)

\section{Shivani Malpotra}

ICAR-National Dairy Research Institute (Deemed University)

\section{Songyukta Shyam}

ICAR-National Dairy Research Institute (Deemed University)

\section{Deepak Kumar}

ICAR-National Dairy Research Institute (Deemed University)

\section{Manoj Kumar Singh}

ICAR-National Dairy Research Institute (Deemed University)

\section{Prabhat Palta}

ICAR-National Dairy Research Institute (Deemed University)

\section{Research Article}

Keywords: Somatic cell nuclear transfer (SCNT), miRNAs, In-vitro fertilization (IVF), Bovine, RNA sequencing, Gene ontology

Posted Date: May 21st, 2021

DOl: https://doi.org/10.21203/rs.3.rs-523872/v1

License: (c) (i) This work is licensed under a Creative Commons Attribution 4.0 International License. Read Full License

Version of Record: A version of this preprint was published at Genes on March 1st, 2022. See the published version at https://doi.org/10.3390/genes13030453. 


\section{Abstract}

Despite the success of cloning technology in production of offspring across several species, its application on a wide scale is severely limited by the very low offspring rate obtained with cloned embryos. MicroRNAs (miRNAs) expression profile in cloned embryos throughout the embryonic development are reported to deviate from regular pattern. In present study, aimed at determining the dynamics of global expression of miRNA profile in cloned and IVF pre-implantation embryos at different developmental stages i.e 2-cell, 8-cell and blastocyst using next-generation sequencing. The results of this study suggested that there is a profound difference in the global miRNA profile between cloned and IVF embryos. These differences are manifested throughout the course of embryonic development. The cloned embryos differ from their IVF counterparts in the enriched GO terms of Biological Process, Molecular Function, Cellular Component and Protein Class categories in terms of the targets of differentially expressed miRNAs. The major pathways related to embryonic development such as Wnt signaling pathway, apoptosis signaling pathway, FGF signaling pathway, p53 pathway etc. were found to be affected in cloned relative to IVF embryos.

\section{Introduction}

Cloning by somatic cell nuclear transfer (SCNT) is one of the important reproductive technologies which can enable multiplication of elite animals at a pace much faster than the conventional breeding programs. SCNT allows fast multiplication of animals carrying specific alleles for higher milk yield, better disease resistance, neater meat quality and higher reproductive potential. Moreover, this technique can be used for the addition of desirable traits into the breeding population. SCNT is also an integral part of several other allied reproductive technologies such as transgenesis, xenotransplantation, therapeutic cloning and disease modeling etc. ${ }^{30}$. It has also been used for the conservation and restoration of endangered species ${ }^{19,23}$. The birth of the first cloned mammal, 'Dolly', the sheep through SCNT, carried out successfully in 1996, was a watershed moment in the history of cloning ${ }^{49}$. Afterwards, SCNT has been efficaciously employed for cloning of various other mammalian species as well 8,18 .

Although successful live births have been achieved in over 20 mammalian species through SCNT, the cloning technology suffers from the serious problem of very low live birth rate obtained with nuclear transferred (NT) embryos $8,18,22,32$. Since the efforts to address this issue have not been fully successful, cloning by SCNT has not been applied on a large scale. In comparison to the live birth rate of over $40 \%$ obtained with bovine IVF embryos ${ }^{5}$, the corresponding figure for NT embryos is only $9 \%{ }^{1,34}$ to $5-20 \%$ 18,37. Across species, the live birth rate obtained with NT embryos is only $1-6 \% 23,32,37$.

In SCNT, the genetic material of a somatic cell is transferred to an enucleated oocyte. The differentiated nucleus of somatic cell is subjected to dedifferentiation to reach the stage of totipotency. This process of making a differentiated cell totipotent is known as nuclear reprogramming. The resultant totipotent embryo is genetically identical to the donor somatic cell. The primary reason for low cloning efficiency is believed to be incomplete nuclear reprogramming i.e., the process of reversing a differentiated somatic 
nucleus to a totipotent embryonic state after nuclear transfer ${ }^{29,31}$. Nuclear reprogramming essentially involves the abolishment of the expression profile of a differentiated cell and establishment of a new embryo-specific expression. This dramatic change in the gene expression profile involves 10,000 to 12,000 genes which drive the embryonic and fetal development ${ }^{29}$.

The aberrant gene expression in cloned embryos as a consequence of incomplete nuclear reprogramming may be partly due to alteration in the expression profile of microRNAs (miRNAs). miRNAs are a class of small non-coding RNAs which are one of the most important molecules involved in regulation of gene expression and generally, one gene can be regulated by several miRNAs, and one miRNA can regulate the expression of several target genes ${ }^{3}$. miRNAs are $\sim 22$ nucleotides in length, bind to the $3^{\prime}$ untranslated region of mRNAs and control the target gene expression either by translational repression or by mRNA degradation. miRNAs are an important component of the epigenetic changes. For example, epi-miRNAs directly target the epigenetic enzymes or functional protein complexes and thus play an important role in the regulation of DNA methylation or histone modifications ${ }^{11,25}$. miRNAs are also implicated in the regulation of cellular reprogramming through genes involved in epigenetic reprogramming and pluripotency ${ }^{33}$.

miRNAs are involved in many biological processes including proliferation, differentiation, and gene expression regulation, oogenesis ${ }^{17}$ and spermatogenesis ${ }^{14}$. miRNAs are present in human $24,38,50$ bovine ${ }^{45}$ and murine ${ }^{44,51}$ gametes and preimplantation embryos where they play crucial roles in various pathways involved in embryo development. miRNAs are involved in the regulation of many important events in reproduction such as oocyte maturation and fertilization ${ }^{13}$, embryo development $7,15,26$ and maternal-to-embryonic transition ${ }^{28}$.

Since their discovery, miRNAs are one of the most extensively studied molecules. However, our knowledge about miRNA expression during mammalian pre-implantation embryo development and their role in the reprogramming of cloned embryos is still very limited. Several studies have been conducted on the expression analysis of a few selected miRNAs in IVF embryos using methods that can identify only a small number of miRNAs ${ }^{21,46,47}$. A few studies have also been conducted on the whole genome level using microarrays in cloned and IVF embryos at a specific stage of development ${ }^{26,36}$. Elucidation of the global miRNA expression profile of NT embryos and understanding how it differs from that of IVF embryos could identify the abnormalities in the NT embryos and help improve their quality for increasing the live birth rate. To our information, there is only one study of our lab on the comparative global miRNA expression analysis between NT and IVF embryos ${ }^{48}$. Till date, there is no report on the global miRNA expression profile of cloned embryos and its comparison with that of their IVF counterparts at different developmental stages in any species. The present study was, therefore, carried out to study the dynamic of global expression of miRNA profile in cloned and IVF pre-implantation embryos at different developmental stages using next-generation sequencing, predicting the associated networks and pathways in pre-implantation embryos development and validating the important differentially expressed miRNAs in cloned and IVF embryos by real-time PCR. 


\section{Results}

\section{miRNA profiling in bovine embryos}

In the present study, we generated approximately $350 \mathrm{~GB}$ raw data to identify the population of miRNAs present in cloned and IVF embryos at different developmental stages (2-cell, 8-cell and blastocysts) of buffalo. For all the samples, 79.67 to $85.40 \%$ of the total reads got aligned against the reference genome of Bos taurus, UMD 3.1.1 (Supplementary figure 1). The alignment statistics of the three biological replicates each of cloned and IVF embryos are given in Table 1. The number of known and novel miRNAs varied among the three biological replicates of cloned and IVF embryos at each stage (Figure 1). The raw data was normalized and the normalized signal values were used for subsequent data analysis. The Boxwhisker plot showing the distribution of normalized signal values in all the replicates of cloned and IVF embryos at different stages are presented in (Supplementary figure 2). The quality of the sequencing data generated was analyzed by Principal Component Analysis (PCA), which depicted that the 2-cell 8-cell and blastocyst stage embryos were overall, grouped according to their origins (Supplementary figure 3 ). The cloned replicates were clustered together in one group while the IVF replicates were together in another group. The reads obtained were aligned on different chromosomes and the maximum number of reads was found to map on chromosome number 25 for all the three stages (Figure 2). Heat map consisting of all the three biological replicates of 2-cell and 8-cell and blastocysts stage of cloned and IVF were generated using Euclidean distance method of differentially expressed miRNAs with minimum fold change of 2 with $p<0.05$ (Figure 3 ).

\section{Identification of differentially expressed miRNAs in preimplantation embryos}

A total of 244, 247, 252 miRNAs were found to be differentially expressed at 2-cell, 8-cell and blastocyst in cloned relative to IVF embryos respectively. In 2-cell stage, out of 244 miRNAs, 186 were commonly expressed in both cloned and IVF 2-cell stage embryos, 35 miRNAs were expressed exclusively in cloned, whereas and 23 were expressed exclusively in IVF embryos. Similarly, at 8-cell stage 196 miRNAs were commonly expressed in both cloned and IVF 8-cell stage embryos, 27 miRNAs were expressed exclusively in cloned embryos whereas, 24 were expressed, exclusively in IVF embryos. Also, at blastocysts stage 195 were commonly expressed in both cloned and IVF blastocysts, 30 miRNAs were expressed exclusively in cloned whereas, 27 were expressed exclusively, in IVF embryos (Figure 4). The top 5 miRNAs up-regulated in cloned relative to IVF embryos at 2-cell stage were bta-mir-136, bta-mir-1187, bta-mir-431, bta-mir-494 and bta-mir-2474 whereas, the top 5 miRNAs down- regulated were, bta-mir-141, bta-mir-451, bta-mir-340, bta-mir-205 and bta-mir-760. At 8-cell stage cloned embryos, bta-mir-133a-2, bta-mir-431, bta-mir-202, btamir-1973 and bta-mir-282 were found to be among the top 5 upregulated miRNAs whereas, bta-mir-139, bta-mir-214, bta-mir-382, bta-mir-135 and bta-mir-2435 were the top five down-regulated miRNAs relative to IVF embryos. Similarly, in cloned blastocysts bta-mir-1949, bta-mir-1692, bta-mir-431, bta-mir-3956 and bta-mir-664a were the top 5 upregulated miRNAs whereas, were bta-mir-1973, bta-mir-1839, bta-mir-188, bta-mir-126 and bta-mir-592 were the top five down-regulated miRNAs. Top 30 differentially expressed miRNAs with fold change $\geq 2$ at all three developmental stages of cloned embryos with respect to IVF 
counterparts are given in (Supplementary table 1,2, \& 3). In all the three comparisons miRNAs unique to cloned group were downregulated whereas, miRNAs unique to IVF groups were upregulated. MA and volcano plot were also used to visualize the distribution pattern of differentially expressed miRNAs in cloned embryos with respect to IVF preimplantation embryos. Different type of distribution patterns were observed in all the developmental stages of embryo (Figure 5).

In the present study, differential expression was also determined in terms of FC values for all the three stages of embryo development. The total number of differentially expressed miRNAs at different FC values ( $\geq 2$ to $<3$-, $\geq 3$ to $<5$ - and $\geq 5$-folds) in 2-cell, 8-cell and blastocysts stage is given in (Supplementary figure 4) Further, at different FC value, the number of up and down-regulated miRNAs in cloned relative to IVF embryos for all three developmental stages are shown in (Supplementary figure 5), respectively. At $F C \geq 2(p<0.05) 47$ miRNAs were found to differentially expressed in cloned relative to IVF 2-cell stage embryos out of which 31 were up-regulated and 16 were down-regulated. Whereas, in 8-cell stage 33 miRNAs were found to be expressed at significant level $(p \leq 0.05)$ at $F C \geq 220$ were up-regulated whereas 13 were downregulated. In case of cloned blastocyst relative to IVF 30 miRNAs were found to differentially expressed out of which 16 were upregulated and 14 were downregulated at FC $\geq 2(p<0.05)$ (Figure 6).

\section{Identification of commonly and uniquely expressed miRNAs}

In the present study we also investigated the commonly and uniquely expressed miRNAs in cloned and IVF embryos at different FC level. Venn diagrams were used to visualize the miRNAs being expressed commonly between cloned and IVF 2-cell, 8-cell and blastocysts stage embryos and the ones uniquely expressed in the two groups respectively (Supplementary figure 6). A minimum cut off of 2-folds change revealed that 66 miRNAs were expressed differentially out of which 18 were unique to cloned embryos, 23 were unique to IVF embryos and 25 were expressed in both types of embryos. Similarly in 8-cell stage at minimum cut off of 2-folds change revealed that 76 miRNAs were expressed differentially out of which 25 were unique to the cloned embryos, 24 were unique to IVF embryos and 27 were expressed in both types of embryos. Also in case of blastocyst, at FC $\geq 273$ miRNAs were expressed differentially out of which 30 were unique to the cloned blastocysts, 22 were unique to IVF blastocysts and 21 were expressed in both types of blastocysts. From among the commonly expressed miRNAs, those which were up- and down-regulated at different fold change level in cloned relative to IVF embryos are presented in (Supplementary figure 7).

At FC $\geq 2$ and significance level of $p<0.05$, a total of 20 miRNAs were found to be commonly expressed between the two types of embryos out of which 4 were down- regulated and 16 were upregulated in cloned relative to IVF 2-cell stage embryos. Whereas, in 8-cell stage out of 20 commonly expressed miRNAs in both the type of embryos 8 were down-regulated and 12 were up-regulated in cloned relative to IVF embryos. A total of 30 miRNAs were found to be commonly expressed between the two types of blastocysts at a significance level of $p<0.05$, out of which 14 were down-regulated and 16 were up-regulated in cloned relative to IVF blastocysts (Figure 7). 


\section{Gene ontology and KEGG analysis of cloned vs IVF preimplantation embryos}

Using panther classification system, Gene ontology (GO) analysis was performed in order to inspect the biological significance, detailed annotation of gene function, biological process and cellular distribution of the targets of miRNAs expressed differentially between cloned and IVF embryos. Using GO terms, NGS results were summarized to provide insights into the changes in miRNA expression between cloned and IVF embryos at the 2-cell, 8-cell and blastocyst stage. In the present study, the targets of miRNAs expressed differentially at fold change $\geq 2$ in cloned relative to IVF embryos were used for $\mathrm{GO}$ analysis. The categories most enriched under Biological Process GO term were- cellular process, metabolic process, regulation of biological process, response to stimuli. Similarly, in molecular Function GO term categories, of which the most affected ones were- binding activity and catalytic activity. In case of Cellular Component GO term, the cell part, cell and organelle being the most enriched ones (Supplementary Figure 8). In case of protein class GO term, the metabolite interconversion enzyme, protein modifying enzyme, nucleic acid binding protein and gene-specific transcriptional regulator being the most affected ones.

\section{Pathway identification and network analysis}

The KEGG pathway enrichment analysis helped us to demonstrate the relationship between the identified differentially expressing miRNA and their role in developmental processes of the embryos. At 2-cell stage, 126 pathways were detected, the major pathways related to embryonic development which were found to be affected in cloned embryos relative to IVF counterparts. Likewise, 122 pathways were detected at 8-cell stage cloned embryos relative to IVF counterparts. Also, 126 pathways were detected at blastocyst-stage cloned embryos relative to IVF counterparts (Supplementary figure 9). Through KEGG analysis we identified the most significantly enriched pathway during the course of embryo development which included apoptosis, cell cycle, MAPK signaling, mTOR, notch signaling, p53 pathway, PI3K-AKT signaling pathway, RAS signaling pathway, signaling pathways regulating pluripotency of stem cells, TGF beta signaling pathway, ERBB signaling pathway, Toll-like signaling pathway and WNT signaling pathway. Notch signaling pathway was specifically enriched pathway in 2-cell stage cloned embryo relative to IVF embryos.

KEGG analyses also revealed the significantly enriched metabolic pathway during the embryo development were pyrimidine metabolism (bta00240), purine metabolism (bta00230), fatty acid biosynthesis (bta00061), glycolysis/gluconeogenesis (bta00010).

Wnt signaling pathway is one of the important signaling pathway during embryo development. It plays a crucial role in regulating the development process of blastocyst stage. In our study, Wnt pathway was the most affected pathway during the course of embryo development. With the help KEGG Analysis we were also able to identify the target genes of upregulated miRNA which were predominantly enriched in WNT pathway (Figure 8). The total number of genes involved in Wnt signaling pathway and the number of genes affected in each stage is given in Table 2. mir-34, mir-345 and mir-409 were found to be upregulated in cloned embryos of 2-cell stage was predicted to regulate the member of Wnt signaling pathway such as WNT2, WNT9A, WNT3A, WNT7A,WNT7B. ALSO mir- 331, mir-339, mir-342 and mir-345 
were predicted to target FZD2, FZD3, FZD5, and FZD7 at 2-cell stage. In 8-cell stage, mir-486, mir-487 and mir-493 were also detected to target WNT7B, WNT9B genes whereas in case of mir-338, mir-365, mir-371 and mir-378 were also found to target WNT3A, WNT9A, WNT7B and WNT2. Some more miRNAs such as mir-381, mir-455, mir-423, mir-93 and mir-574 were targeting DKK3, DKK4 and DKK1 gene respectively.

\section{Validation of RNA seq data}

In order to validate the RNA-seq data, seven miRNAs, which had been found to be expressed differentially between cloned and IVF embryos at different developmental stages (2-cell, 8-cell and blastocyst) were selected randomly and on the basis of their fold change for validation by qPCR analysis. These miRNAs were mir-218, mir-340 and mir-202 from 2-cell stage, mir-214, mir-96 and mir-139 from 8-cell stage and mir-370 from blastocyst stage. The two housekeeping miRNAs i.e., UniSp6, and miR-423 were used for the normalization of target miRNAs. The pattern and magnitude of relative expression level were found to be similar in RNA-seq and qPCR data (Figure 9).

\section{Discussion}

To our information, there is no report on the comparative global miRNA profile of cloned and IVF embryos except for the report of Viviyan (2016) who compared the global miRNA profile between cloned and IVF at the blastocyst stage in buffalo using NGS. This author reported that At with FC $\geq 2$ ( $p \leq 0.2), 37$ miRNAs were up-regulated and 19 were down-regulated in cloned blastocysts. Our results, in combination with those of Viviyan ${ }^{48}$ show that the miRNA expression profiles of IVF and cloned buffalo blastocysts are quite different from each other.

Viviyan ${ }^{48}$ also carried out GO analysis of the NGS data and showed that 47 categories under Biological processes, 28 under Cellular components and 22 under Molecular functions were enriched. Our study showed that 22 categories under Biological Process, 14 under Cellular components and 8 under Molecular functions were enriched. In addition, we found that 22 categories were enriched under Protein Class. This author reported that 8 pathways that were affected the most (based on their role in preimplantation development) were Cell Cycle, Apoptosis, Signaling pathways regulating pluripotency of stem cells, MAPK signaling pathway, Notch signaling pathway, WNT signaling pathway, TGF-beta signaling pathway, and JAK-STAT signaling pathway. Our results are in agreement with this study as it was found in the present study that the major pathways related to embryonic development which were found to be affected in cloned blastocyst-stage embryos relative to IVF counterparts were apoptosis signaling pathway, Wnt signaling pathway, Ras Pathway, CCKR signaling map, TGF-beta signaling pathway, PDGF signaling pathway, Integrin signaling pathway, FGF signaling pathway, Cadherin signaling pathway, EGF receptor signaling pathway.

The mammalian embryo development is initiated after fertilization. The initial developmental control is provided by maternal factors present in egg cytoplasm while the embryonic genome stays in dormant state. Eventually, the zygotic genome is activated, followed by the release of embryonic gene products 
and parallel degradation of maternal factors. This parallel degradation of maternal gene products and generation of zygotic gene products is called maternal-to-zygotic transition (MZT). This is sometimes also termed as maternal-to-embryonic transition (MET), embryonic genome activation (EGA) or zygotic gene activation (ZGA). MZT is constituted of series of events; starting from fertilization till the whole embryonic genome is activated and maternal genes are depleted ${ }^{10,20,43}$. Zygotic gene activation occurs at different interval of time depending upon the animal species. Primarily, oocyte serves as the reservoir for the maternal transcripts and proteins. The potential of oocyte for the reprogramming of differentiated cell nuclei to embryonic nuclei has been proved in somatic cell nuclear transfer technique. EGA occurs at 2-cell stage in mouse ${ }^{39}$, at 4- to 8-cell stage in human ${ }^{9}$ and pig ${ }^{4}$ and at 8- to 16 -cell stage in cow ${ }^{12}$ and sheep ${ }^{6}$.

MZT plays a vital role during embryonic development as it synchronizes the cell division and embryonic genome activation preparing embryo for cell differentiation and further development. The elementary role of early embryonic genes is to supply the molecular substrate to start gastrulation, which results in the well-organized cell movements and germ layer specification. After the activation of zygotic genes the animal initiates to establish different cell fates and specific morphological patterns. It is indicated MZT consist of three different phases. First phase includes the decay of maternally inherited oocyte specialized transcripts. Generally, the fully grown oocyte and 1-cell embryo are often considered transcriptionally silent. During oogenesis, oocyte synthesis and gathers its own transcripts and protein and later these become maternal products which further control the developmental process until the embryonic genome is activated ${ }^{2}$. In the second phase of MZT, the maternal transcripts are substituted from zygotic genes. This transition period is one of the most critical steps involved in the embryo development. In this period the transcription control of embryo development is eventually transmitted to zygotic transcripts from maternal. In the third and final phase of MZT, transcripts unique to zygote are generated, which are known as zygotic-specific transcripts causing the change in the dynamics of embryo development.

\section{Methods}

\section{Ethics statement}

All methods were carried out in accordance with guidelines of CPCSEA (Committee for the Purpose of Control and Supervision on Experiments on Animals) with due approval from the Institutional Animal Ethics Committee (IAEC) of ICAR-National Dairy Research Institute, Karnal, Haryana with approval number (F.No. 43-IAEC-18-1), dated 13.10.2018). The experimental animals used to obtain ovaries for this study were native Indian buffaloes breed 'Murrah'. Efforts were made to minimize animals' pain and suffering in abattoir at Delhi, India. Also, we tried to reduce the number of buffaloes required to complete this study.

The present study was designed with two experimental groups' i.e. cloned embryos and IVF embryos of buffalo produced in vitro. Cloned embryos were collected at different developmental stages (2-cell, 8-cell and blastocyst) at different interval post in vitro culture. Embryos produced by IVF (2-cell, 8-cell and 
blastocyst) were used as control in this study. Both morphological and physiological evaluation was done before selecting oocytes. Compact cumulus-oocyte-complexes (COCs) with 2-8 mm diameter in size, unexpanded cumulus mass having $\geq 2$ layers of cumulus cells, and with homogenous, evenly granular ooplasm were used for cloning and IVF purpose. Brilliant Cresyl Blue (BCB) stain was used to select oocytes with high developmental competence. After in vitro culture, cloned embryos at 2-cell, 8-cell and blastocyst stage were collected at $14-16 \mathrm{~h}, 36-40 \mathrm{~h}$ and $8^{\text {th }}$ day post in vitro culture (IVC), respectively. The embryos were washed thrice with DEPC-treated water and stored at $-196^{\circ} \mathrm{C}$ in liquid nitrogen until further use. IVF embryos at 2-cell, 8-cell and blastocyst stage were collected at 24-26 $\mathrm{h}, 68-72 \mathrm{~h}$ and $8^{\text {th }}$ day post IVC, respectively. In this study, the total number of cell present in each pool of 2-cell, 8-cell and blastocysts stage produced by Hand-guided cloning and IVF was 1000, 2520 and 6000 respectively for RNA-seq. For real-time PCR, 2-cell, 8-cell and blastocyst stage of cloned and IVF embryos contained 400, 720 and 6000 number of cells per pool. Method and sample size involved in vitro production of cloned and IVF embryos is described as follows:

\section{Production of preimplantation embryos by HMC}

The useable quality of COCs obtained from abattoir buffalo ovaries based on their morphology and BCB treatment ${ }^{27}$ were matured with the IVM medium (TCM-199 + 10\% FBS $+5 \mu \mathrm{g} / \mathrm{mL} \mathrm{FSH}-\mathrm{p}+1 \mu \mathrm{g} / \mathrm{mL}$ estradiol- $17 \beta+0.81 \mathrm{mM}$ sodium pyruvate $+5-10 \%$ buffalo follicular fluid $+50 \mu \mathrm{g} / \mathrm{ml}$ gentamicin sulfate) . Ear skin fibroblast cells from a buffalo bull (Mu-4093) from CIRB, Hisar, were used as donor cells for HMC which were established and characterized by a standard protocol ${ }^{40}$. The cells were synchronized in $\mathrm{G} 1$ stage of cell cycle by growing them in culture to full confluence for contact inhibition as described previously ${ }^{41}$. HMC, which included IVM, cumulus/zona removal, manual enucleation, fusion, activation, and in vitro culture (IVC), was performed as described earlier ${ }^{42}$.

\section{Production of preimplantation embryos by IVF}

For IVF embryos, usable quality COCs obtained from slaughtered buffalo ovaries were subjected to BCB staining to obtain COCs with high developmental competence. $\mathrm{BCB}+$ oocytes were subjected to IVF and IVC as described previously ${ }^{35}$.

For IVF, semen of the same bull (Mu-4093) whose tail fibroblast cells were used as nuclear donor cells for HMC to produce genetically half-identical embryos to minimize the genetic variability between the embryos produced by the two approaches.

\section{Extraction of total RNA for small-RNA sequencing}

Total RNA was isolated from respective pools of cloned and in vitro fertilized embryos using the Single Cell RNA Purification Kit (NORGEN, Thorold, ON, Canada) as per manufacturer's instructions. Quantification of RNA and purity was analysed qubit reads. The RNA yield varied between 100 and 150 ng for each pool and the $260 / 280$ value was found to be between 1.79 and 1.90 . Library preparation, 
sequencing and data analysis was carried out by commercial sequencing service provider (DNA Xperts, New Delhi, India.). Quality of RNA isolated for sequencing from biological replicates ( $n=4$ each) of cloned (2-cell, 8-cell and blastocysts) and IVF (2-cell, 8-cell and blastocysts) embryos was examined on Agilent 2100 Bioanalyzer (Agilent technologies, Santa Clara, CA, USA) using Agilent Total RNA 6000 pico series kit. RNA samples with RIN value ranging from 6 to 10 were used further for library preparation step.

\section{cDNA library preparation and sequencing}

According to the manufacturer's instructions, QIAseq miRNA Library Kit, (Thermo Fisher Scientific NGS Systems) was used for cDNA library preparation by taking equimolar molar amount of RNA from cloned and IVF 2-cell, 8-cell and blastocyst stage embryos. The library was prepared in single end 1x50 bp format with average fragment length of approx. 150 bp. Agilent DNA High Sensitivity 1000 kit was employed for the quality control analysis of library. Illumina HiSeq 2500 instrument was used for sequencing run. Quality check (QC) of raw single end reads was carried out using FastQC. All the reads were found to be of good quality based upon the Phred score values, which were greater than 20 .

\section{miRNome data analysis}

UEA small RNA workbench (version4.5) software was used for analysis of raw data. The clean reads were aligned to Bos Taurus reference genome, UMD 3.1.1. The known miRNAs were identified using miRProf in miRBase 22.1 and the novel miRNAs were identified using miRCat software. The miRNome data analysis workflow employed in the present study consisted of following major steps viz., raw data mapping onto the reference genome, sequence of Bos Taurus, no. of mapped reads to each known miRNA calculation by mirProf, raw and normalized read counts obtained as output of mirProf, loading of read counts data into DESeq2 software, normalization of data, identification of differentially expressed miRNAs based upon fold change and P-adjusted value criteria, classification/clustering of genes. The gene ontology enrichment analysis was done by using Panther Classification System. Targets genes were identified using TargetScan software. Detailed pathway analysis was done using Kyoto Encyclopedia of Genes and Genome (KEGG) analysis was used for pathway analysis.

\section{Validation of RNA-seq data by qPCR}

RNA was isolated from the three biological replicate of cloned and IVF 2-cell, 8-cell and blastocyst stage consisting of 600,270 and 90 , embryos respectively for qRT-PCR analysis as described above. RNA purity for each pool was determined by A260/280 ratio for each replicate. The sample with ratio between 1.9 and 2.1 was considered for qRT-PCR. For miRNA expression analysis CDNA preparation was done using miRCURY LNA RT kit (Qiagen, Maryland, USA) according to the manufacturer's instructions. $5 \mathrm{ng} / \mu \mathrm{L}$ of template RNA was used for CDNA preparation followed by the incubation of reaction mixture for 60 mins at $42^{\circ} \mathrm{C}$. Heat inactivation of reverse transcriptase was done for 5 mins at $95^{\circ} \mathrm{C}$. miRNA cDNA was then immediately cooled to $4^{\circ} \mathrm{C}$ and stored at $20^{\circ} \mathrm{C}$ for further use. For miRNA qPCR analysis, Locked nucleic acid $\left(\mathrm{LNA}^{\mathrm{TM}}\right)$ based universal primers were used (Qiagen, Maryland, USA) (Supplementary table 4). 


\section{Declarations}

\section{Acknowledgments}

We thank SERB-DST Project 4001/511 for providing financial support. P.Goel was supported by fellowship from ICAR-NDRI, Karnal. D. Kumar was recipients of ICAR-NDRI, Karnal whereas, S. Shyam and S. Malpotra was supported by fellowship from NFHST, Ministry of Tribal Affairs, Govt. of India and ICMR, Govt. of India respectively.

\section{Author's contribution}

P. Goel and S. Malpotra wrote the manuscript, S. Shyam, D. Kumar and M.K. Singh contributed in lab related work and P. Palta contributed in designing the project and provided guidance.

\section{Conflict of interest}

The authors do not have any conflict of interest.

\section{References}

1. Akagi, S., Geshi, M. \& Nagai, T. Recent progress in bovine somatic cell nuclear transfer. Animal science journal, 84(3), 191-199 (2013). https://doi.org/10.1111/asj.12035.

2. Bachvarova, R. Gene expression during oogenesis and oocyte development in mammals. Oogenesis 453-524 (1985) Springer, Boston, MA.

3. Bartel, D.P. MicroRNAs: target recognition and regulatory functions. Cel/136(2), 215-233 (2009). https://doi.org/10.1016/j.cell.2009.01.002.

4. Braude, P., Bolton, V. \& Moore, S. Human gene expression first occurs between the four-and eight-cell stages of preimplantation development. Nature332(6163), 459-461 (1988).

5. Campbell, K.H.S. et al. Somatic cell nuclear transfer: past, present and future perspectives. Theriogenology68, S214-S231 (2007). https://doi.org/10.1016/j.theriogenology.2007.05.059.

6. Crosby, I.M., Gandolfi, F. \& Moor, R.M. Control of protein synthesis during early cleavage of sheep embryos. Reproduction82(2), 769-775 (1988). https://doi.org/10.1530/jrf.0.0820769

7. Coutinho, L.L. et al. Discovery and profiling of bovine microRNAs from immune-related and embryonic tissues. Physiol genomics29(1), 35-43 (2007). https://doi.org/10.1152/physiolgenomics.00081.2006

8. Czernik, M., Anzalone, D.A., Palazzese, L., Oikawa, M. \& Loi, P. Somatic cell nuclear transfer: failures, successes and the challenges ahead. Int J Dev Biol., 63(3-4-5), 123-130 (2019). 1387/ijdb.180324mc

9. Davis, D.L. Culture and storage of pig embryos. J reprod Suppl., 33, 115-124 (1985).

10. Davidson, E.H. Gene activity in early development. Elsevier 2012. 
11. Denis, H., Ndlovu, M.N. \& Fuks, F. Regulation of mammalian DNA methyltransferases: a route to new mechanisms. EMBO reports12(7), 647-656 (2011). https://doi.org/10.1038/embor.2011.110

12. Frei, R.E., Schultz, G.A. \& Church, R.B. Qualitative and quantitative changes in protein synthesis occur at the 8-16-cell stage of embryogenesis in the cow. Reproduction86(2), 637-641 (1989). https://doi.org/10.1530/jrf.0.0860637

13. Gilchrist, G.C., Tscherner, A., Nalpathamkalam, T., Merico, D. \& LaMarre, J. MicroRNA expression during bovine oocyte maturation and fertilization. Int J Mol Sci, 17(3), 396 (2016). https://doi.org/10.3390/ijms17030396

14. Hayashi, K. et al. MicroRNA biogenesis is required for mouse primordial germ cell development and spermatogenesis. PloS one, 3(3), 1738 (2008). https://doi.org/10.1371/journal.pone.0001738

15. Hossain, M.M., Salilew-Wondim, D., Schellander, K. \& Tesfaye, D. The role of microRNAs in mammalian oocytes and embryos. Anim Reprod Sci., 134(1-2), 36-44 (2012). https://doi.org/10.1016/j.anireprosci.2012.08.009

16. Cuthbert, J.M., Russell, S.J., White, K.L. \& Benninghoff, A.D. The maternal-to-zygotic transition in bovine in vitro-fertilized embryos is associated with marked changes in small non-coding RNAs. Biol Reprod., 100(2), 331-350 (2019). https://doi.org/10.1093/biolre/ioy190.

17. Kaneda, M., Tang, F., O'Carroll, D., Lao, K. \& Surani, M.A. Essential role for Argonaute2 protein in mouse oogenesis. Epigenetics Chromatin, 2(1), 9 (2009). https://doi.org/10.1186/1756-8935-2-9.

18. Keefer, C.L. Artificial cloning of domestic animals. Proc Natl Acad Sci U S A, 112(29), 8874-8878 (2015). https://doi.org/10.1073/pnas.1501718112.

19. Lagutina, I., Fulka, H., Lazzari, G. \& Galli, C. Interspecies somatic cell nuclear transfer: advancements and problems. Cell Reprogram, 15(5), 374-384 (2013). https://doi.org/10.1089/cell.2013.0036.

20. Lee, M.T., Bonneau, A.R. \& Giraldez, A.J. Zygotic genome activation during the maternal-to-zygotic transition. Annu Rev Cell Dev Biol. 30, 581-613 (2014). https://doi.org/10.1146/annurev-cellbio100913-013027

21. Qi, L. et al. miR-370 is stage-specifically expressed during mouse embryonic development and regulates Dnmt3a. FEBS Lett, 587(6), 775-781 (2013). https://doi.org/10.1016/j.febslet.2013.01.070.

22. Loi, P., luso, D., Czernik, M. \& Ogura, A. A new, dynamic era for somatic cell nuclear transfer? Trends Biotechnol., 34(10), 791-797 (2016). https://doi.org/10.1016/j.tibtech.2016.03.008.

23. Loi, P., Modlinski, J.A. \& Ptak, G. Interspecies somatic cell nuclear transfer: a salvage tool seeking first aid. Theriogenology, 76(2), 217-228 (2011). https://doi.org/10.1016/j.theriogenology.2011.01.016.

24. McCallie, B., Schoolcraft, W.B. \& Katz-Jaffe, M.G. Aberration of blastocyst microRNA expression is associated with human infertility. Fertil Steril., 93(7), 2374-2382 (2010). https://doi.org/10.1016/j.fertnstert.2009.01.069.

25. Memari, F. et al. Epigenetics and Epi-miRNAs: potential markers/therapeutics in leukemia. Biomed Pharmacother., 106, 1668-1677 (2018). https://doi.org./10.1016/j.biopha.2018.07.133 
26. Mineno, J. et al. The expression profile of microRNAs in mouse embryos. Nucleic Acids Res., 34(6), 1765-1771 (2006). https://doi.org/10.1093/nar/gkl096.

27. Mohapatra,K., Sandhu, A., Singh, K.P., Singla, S.K., Chauhan, M.S., Manik, R. and Palta, P. 2015. Establishment of trophectoderm cell lines from buffalo (Bubalus bubalis) embryos of different sources and examination of in vitro developmental competence, quality, epigenetic status and gene expression in cloned embryos derived from them. PLoS One, 10(6):e0129235.

28. Mondou, E., Dufort, I., Gohin, M., Fournier, E. \& Sirard, M.A. Analysis of microRNAs and their precursors in bovine early embryonic development. Mol Hum Reprod., 18(9), 425-434 (2012). https://doi.org/10.1093/molehr/gas015

29. Niemann, H. Epigenetic reprogramming in mammalian species after SCNT-based cloning. Theriogenology, 86(1), 80-90 (2016).https://doi.org/10.1016/j.theriogenology.2016.04.021

30. Niemann, H. \& Lucas-Hahn, A. Somatic cell nuclear transfer cloning: practical applications and current legislation. Reprod Domest Anim., 47, 2-10 (2012). https://doi.org/10.1111/j.14390531.2012.02121.x

31. Niemann, H., Tian, X.C., King, W.A. \& Lee, R.S. Focus on Mammalian Embryogenomics Epigenetic reprogramming in embryonic and foetal development upon somatic cell nuclear transfer cloning. Reproduction, 135, 151-163 (2008).

32. Ogura, A., Inoue, K. \& Wakayama, T. Recent advancements in cloning by somatic cell nuclear transfer. Philos Trans R Soc Lond B Biol Sci., 368(1609), 20110329 (2013). https://doi.org/10.1098/rstb.2011.0329

33. Onder, T.T. \& Daley, G.Q. microRNAs become macro players in somatic cell reprogramming. Genome Med., 3(6), 40 (2011). https://doi.org/10.1186/gm256

34. Panarace, M. et al. How healthy are clones and their progeny: 5 years of field experience. Theriogenology, 67(1), 142-151 2007. https://doi.org/10.1016/j.theriogenology.2006.09.036

35. Rashmi, Sah, S., Shyam, S., Singh, M.K. \& Palta, P. Treatment of buffalo (Bubalus bubalis) SCNT embryos with microRNA-21 mimic improves their quality and alters gene expression but does not affect their developmental competence. Theriogenology, 126, 8-16 (2019). https://doi.org/10.1016/j.theriogenology.2018.11.025

36. Rodríguez-Alvarez, L. et al. Differential gene expression in bovine elongated (Day 17) embryos produced by somatic cell nucleus transfer and in vitro fertilization. Theriogenology, 74(1), 45-59 (2010). https://doi.org/10.1016/j.theriogenology.2009.12.018

37. Rodriguez-Osorio, N., Urrego, R., Cibelli, J.B., Eilertsen, K. \& Memili, E. Reprogramming mammalian somatic cells. Theriogenology, 78(9), 1869-1886 (2012). https://doi.org/10.1016/j.theriogenology.2012.05.030

38. Rosenbluth, E.M. et al. MicroRNA expression in the human blastocyst. Fertil Steril, 99(3), 855-861 (2013). https://doi.org/10.1016/j.fertnstert.2012.11.001 
39. Schultz, R.M. Regulation of zygotic gene activation in the mouse. Bioessays, 15(8), 531-538 (1993). https://doi.org/10.1002/bies.950150806

40. Selokar, N.L. et al. Hope for restoration of dead valuable bulls through cloning using donor somatic cells isolated from cryopreserved semen. PloS one, 9(3), e90755 (2014). https://doi.org/10.1371/journal.pone.0090755

41. Selokar, N.L., Saini, M., Muzaffer, M., Krishnakanth, G., Saha, A.P., Chauhan, M.S., Manik, R.S., Palta, P., Madan, P. and Singla, S.K. Roscovitine treatment improves synchronization of donor cell cycle in G0/G1 stage and in vitro development of handmade cloned buffalo (Bubalus bubalis) embryos. Cell. Reprogram.,14:146-154.

42. Selokar, N.L. et al. Effect of post-fusion holding time, orientation and position of somatic cellcytoplasts during electrofusion on the development of handmade cloned embryos in buffalo (Bubalus bubalis). Theriogenology, 78(4), 930-936 (2012b). https://doi.org/10.1016/j.theriogenology.2012.03.018

43. Tadros, W. \& Lipshitz, H.D. The maternal-to-zygotic transition: a play in two acts. Development, 136(18), 3033-3042 (2009). 10.1242/dev.033183

44. Tang, F. et al. Maternal microRNAs are essential for mouse zygotic development. Genes Dev., 21(6), 644-648 (2007). http://www.genesdev.org/cgi/doi/10.1101/gad.418707

45. Tesfaye, D. et al. Identification and expression profiling of microRNAs during bovine oocyte maturation using heterologous approach. Mol Reprod Dev., 76(7), 665-677 (2009). https://doi.org/10.1002/mrd.21005

46. Tripurani, S.K. et al. MicroRNA-196a regulates bovine newborn ovary homeobox gene (NOBOX) expression during early embryogenesis. BMC Dev Biol., 11(1), 25 (2011). https://doi.org/10.1186/1471-213X-11-25

47. Tripurani, S.K., Wee, G., Lee, K.B., Smith, G.W. \& Wang, L. MicroRNA-212 post-transcriptionally regulates oocyte-specific basic-helix-loop-helix transcription factor, factor in the germline alpha (FIGLA), during bovine early embryogenesis. PLoS One, 8(9), e76114 (2013). https://doi.org/10.1371/journal.pone.0076114

48. Viviyan, S. miRNA expression analysis in cloned buffalo embryos. Ph.D. thesis submitted to D.R.I, Karnal (Deemed University) (2016).

49. Wilmut, I., Schnieke, A.E., McWhir, J., Kind, A.J. \& Campbell, K.H. Viable offspring derived from fetal and adult mammalian cells. Nature, 385(6619), 810-813 (1997). https://doi.org/10.1038/385810a0

50. Xu, Y.W. et al. Differentially expressed micoRNAs in human oocytes. J Assist Reprod Genet., 28(6), 559-566 (2011). https://doi.org/10.1007/s10815-011-9590-0

51. Yang, Y. et al. Determination of microRNAs in mouse preimplantation embryos by microarray. Dev Dyn., 237(9), 2315-2327 (2008). https://doi.org/10.1002/dvdy.21666

\section{Tables}


Table 1: Alignment statistics of cloned and IVF embryos at 2-, 8-cell and blastocyst stage with each replicate containing 500 embryos.

\begin{tabular}{|c|c|c|c|c|c|}
\hline Param & $\begin{array}{l}\text { Total number } \\
\text { of reads }\end{array}$ & $\begin{array}{l}\text { Distinct number } \\
\text { of reads }\end{array}$ & $\begin{array}{l}\text { Aligned } \\
\text { reads (\%) }\end{array}$ & $\begin{array}{l}\text { Unaligned } \\
\text { reads (\%) }\end{array}$ & $\begin{array}{l}\text { Maximum read } \\
\text { length }\end{array}$ \\
\hline $2 \mathrm{CC}-1$ & $17,307,418$ & $2,32,369$ & 79.67 & 20.33 & 50 \\
\hline $2 \mathrm{CC}-2$ & $15,731,948$ & $2,27,625$ & 79.82 & 20.18 & 50 \\
\hline $2 \mathrm{CC}-3$ & $16,309,020$ & $3,92,869$ & 81.38 & 18.62 & 50 \\
\hline $2 \mathrm{Cl}-1$ & $13,422,098$ & $3,14,645$ & 83.54 & 16.46 & 50 \\
\hline $2 \mathrm{Cl}-2$ & $12,758,526$ & $3,11,976$ & 83.66 & 16.34 & 50 \\
\hline $2 \mathrm{Cl}-3$ & $11,893,184$ & $2,25,993$ & 85.40 & 14.60 & 50 \\
\hline $8 C C-1$ & $17,409,668$ & $3,64,676$ & 81.35 & 18.65 & 50 \\
\hline 8CC-2 & $12,483,044$ & $3,31,093$ & 82.16 & 17.84 & 50 \\
\hline 8CC-3 & $14,840,784$ & $3,51,968$ & 81.80 & 18.20 & 50 \\
\hline $8 \mathrm{Cl}-1$ & $13,822,944$ & $2,34,722$ & 83.31 & 16.69 & 50 \\
\hline $8 \mathrm{Cl}-2$ & $13,308,848$ & $2,37,288$ & 83.49 & 16.51 & 50 \\
\hline $8 \mathrm{Cl}-3$ & $15,839,750$ & $3,66,705$ & 83.71 & 16.29 & 50 \\
\hline BL-1 & $12,608,590$ & $2,85,577$ & 85.59 & 14.41 & 50 \\
\hline BL-2 & $10,784,686$ & $2,73,300$ & 85.92 & 14.08 & 50 \\
\hline BL-3 & $10,875,612$ & $2,76,876$ & 84.20 & 15.80 & 50 \\
\hline BLI-1 & $12,380,724$ & $2,50,071$ & 82.35 & 17.65 & 50 \\
\hline BLI-2 & $12,573,252$ & $2,52,929$ & 82.39 & 17.61 & 50 \\
\hline BLI-3 & $14,146,486$ & $3,55,853$ & 83.23 & 16.77 & 50 \\
\hline
\end{tabular}

Table 2: Genes annotated in WNT signaling pathway in cloned embryos relative to IVF embryos

\begin{tabular}{|lllll|}
\hline Stage & Total genes & Annotated genes in Wnt pathway & Log fold change & P-value \\
\hline 2CC-vs-2Cl & 2276 & $31(1.37 \%)$ & 1.06 & $6.97 \mathrm{E}-01$ \\
\hline 8 CC-vs-8Cl & 1934 & $30(1.55 \%)$ & 1.24 & $2.45 \mathrm{E}-01$ \\
\hline BL-vs-BLI & 2631 & $41(1.56 \%)$ & 1.22 & $2.37 \mathrm{E}-01$ \\
\hline
\end{tabular}


Figures

(A) Known miRNAs

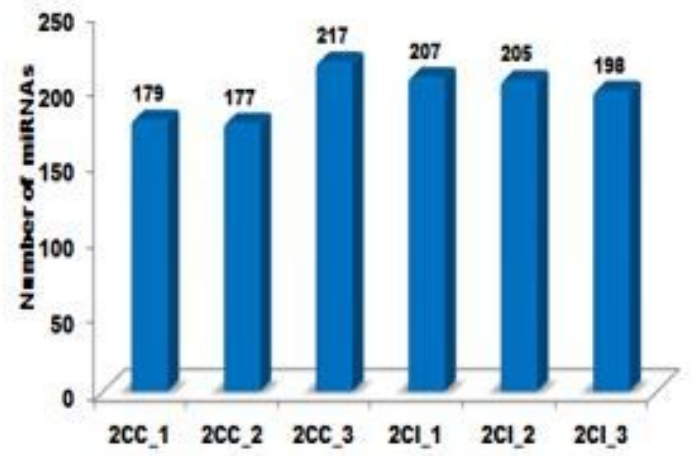

(c)

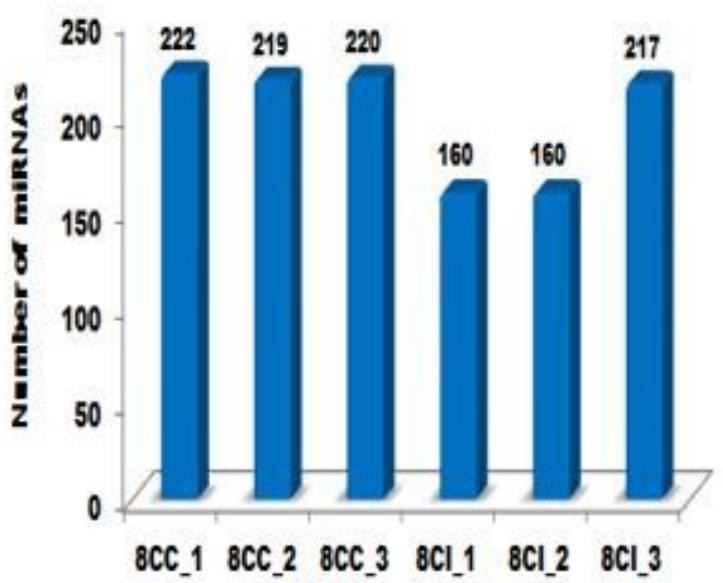

(E)

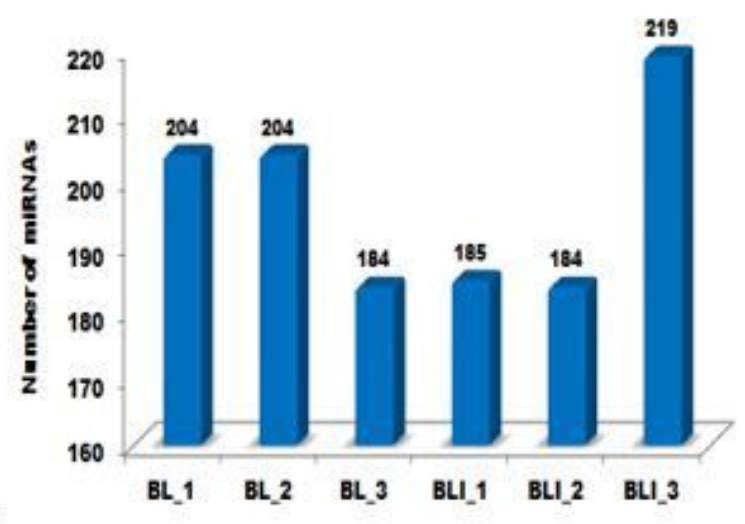

(B)

Novel miRNAs

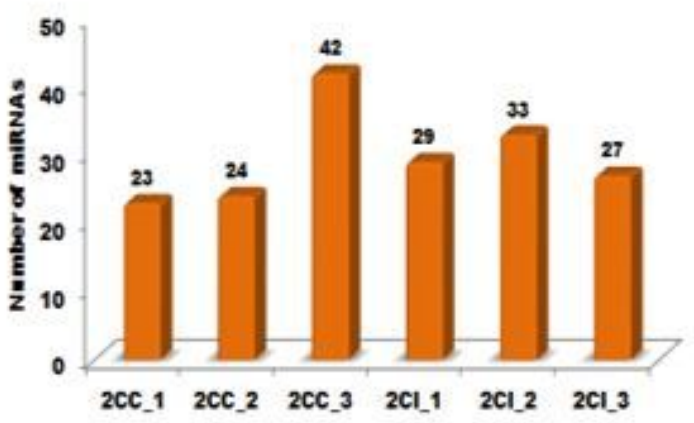

(D) Novel miRNAs

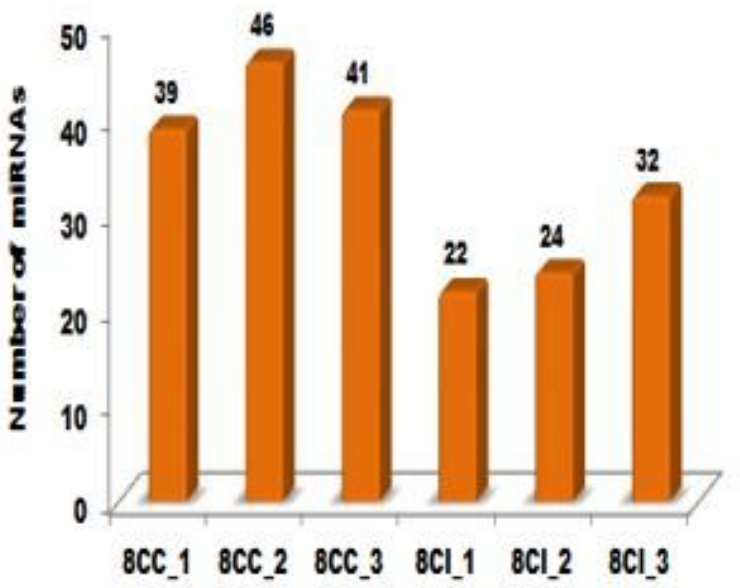

(F)

Novel miRNAs

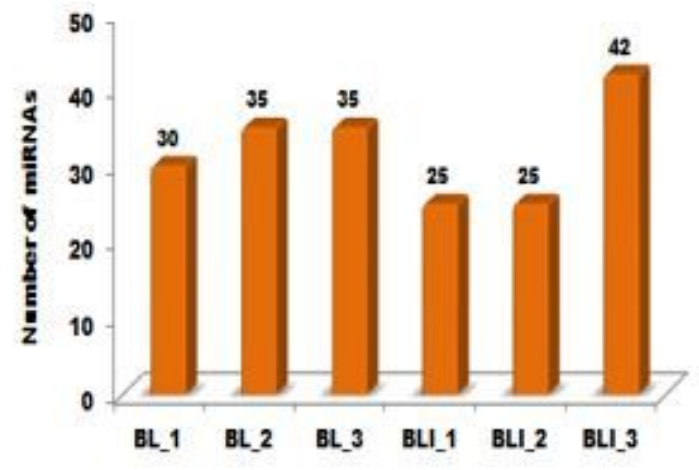

Figure 1 
Number of known and novel miRNAs in the three replicates of (A\&B) 2-cell, (C\&D) 8-cell and (E\&F) Blastocyst stage cloned embryos.

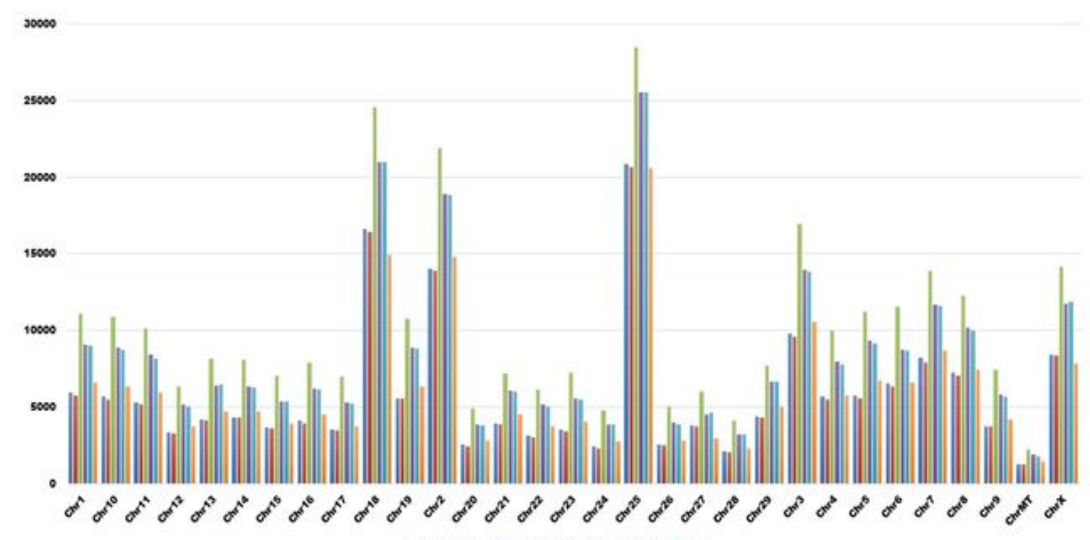

(A) $=200,1=200,2=20 c, 3=2 a, 1, n=2 c_{1}, 2=2 a, 3$

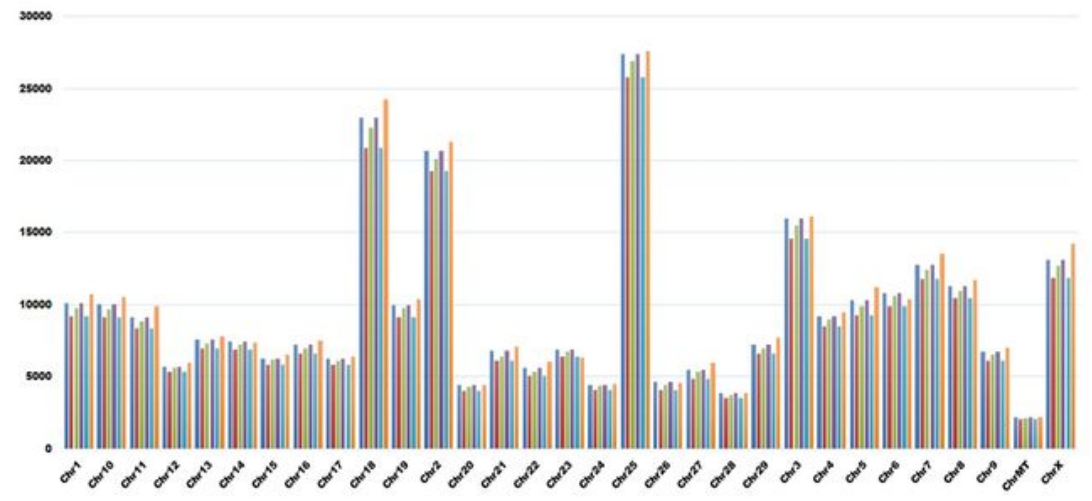

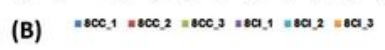

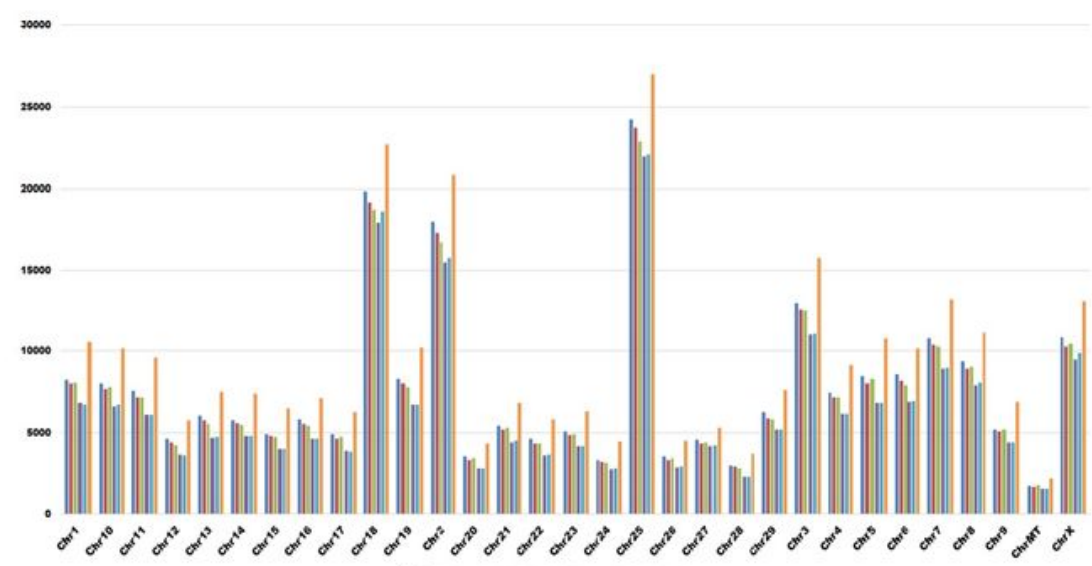

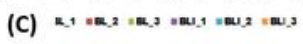

\section{Figure 2}

Reads of (A) 2-cell stage (B) 8-cell stage (C) blastocyst stage cloned embryos were mapped to different chromosomes. Maximum number of reads were found to map on chromosome number 25. 

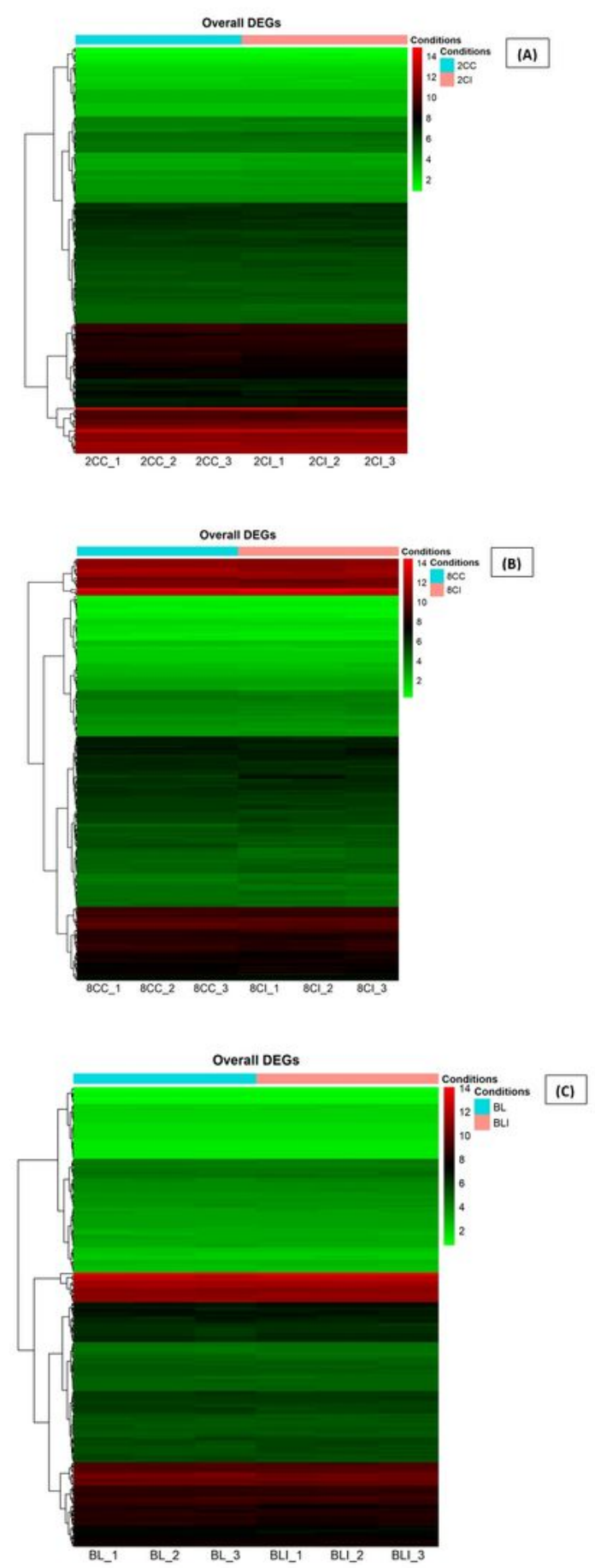

\section{Figure 3}

Hierarchical clustering analysis of miRNAs expressed differentially in cloned and IVF embryos (FC $\geq 2$, $p<0.05)$ reflecting similar expression pattern between replicates of same origin. A) For 2-cell stage embryos, cloned replicates named 2CC_1 and 2CC_2 were clustered together in a single group which further grouped with 2CC_3. Similarly, IVF replicates 2Cl_1 and 2Cl_2 clustered together in a single group and further grouped with 2Cl_3. B) For 8-cell stage, cloned replicates named 8CC_1 and 8CC_2 were 
clustered together in a single group which further grouped with 8CC_3. Similarly, IVF replicates, 8CI_1 and 8Cl_2 were clustered together in a single group and further grouped with 8Cl_3. C) For blastocyst stage, cloned replicates BL_1 and BL_2 were clustered together in a single group which further grouped with BL_3. Similarly, IVF replicates, BLI_1 and BLI_2 clustered together in a single group and further grouped with BLI_3.

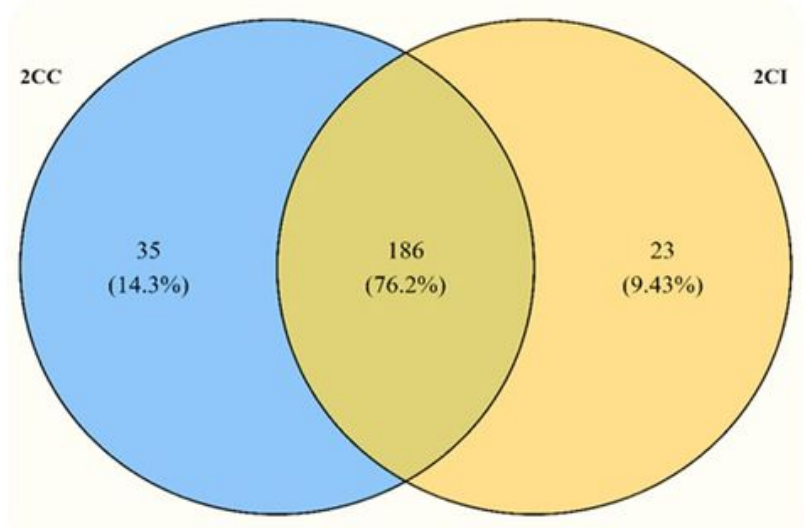

(A)

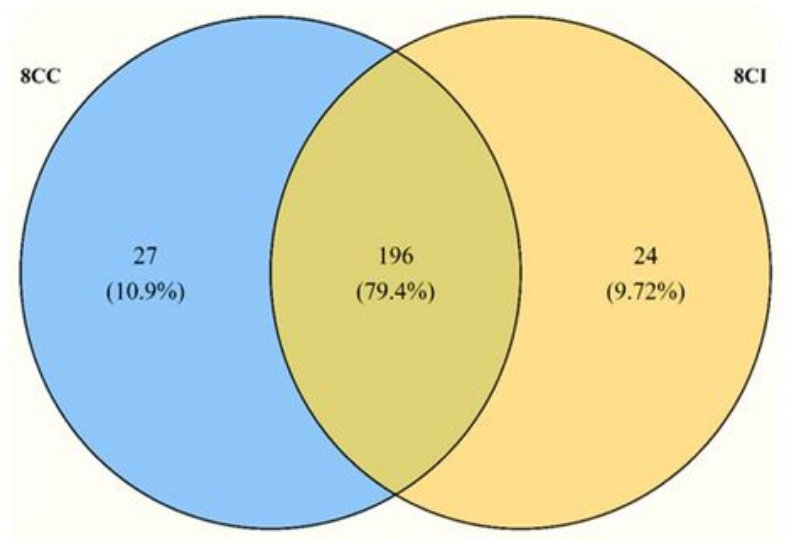

(B)

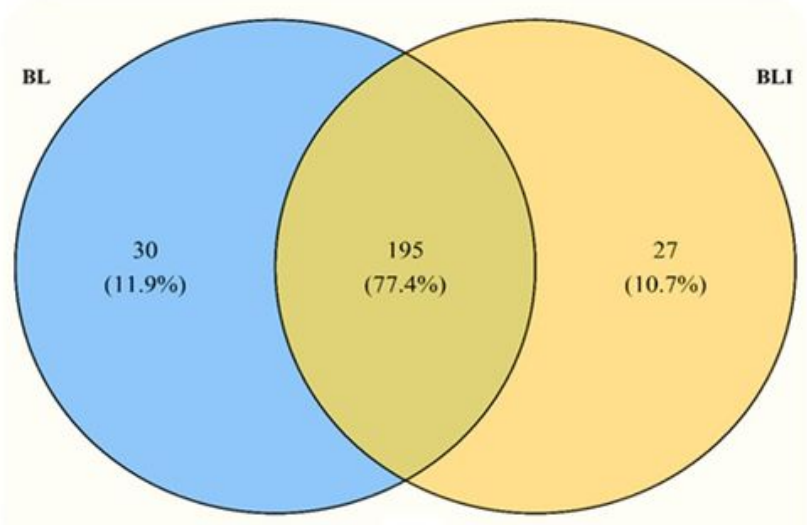

(C)

Figure 4 
Venn diagram showing the overall commonly and uniquely expressed miRNAs in cloned and IVF (A) 2-cell stage (B) 8-cell stage (C) blastocyst-stage embryos.
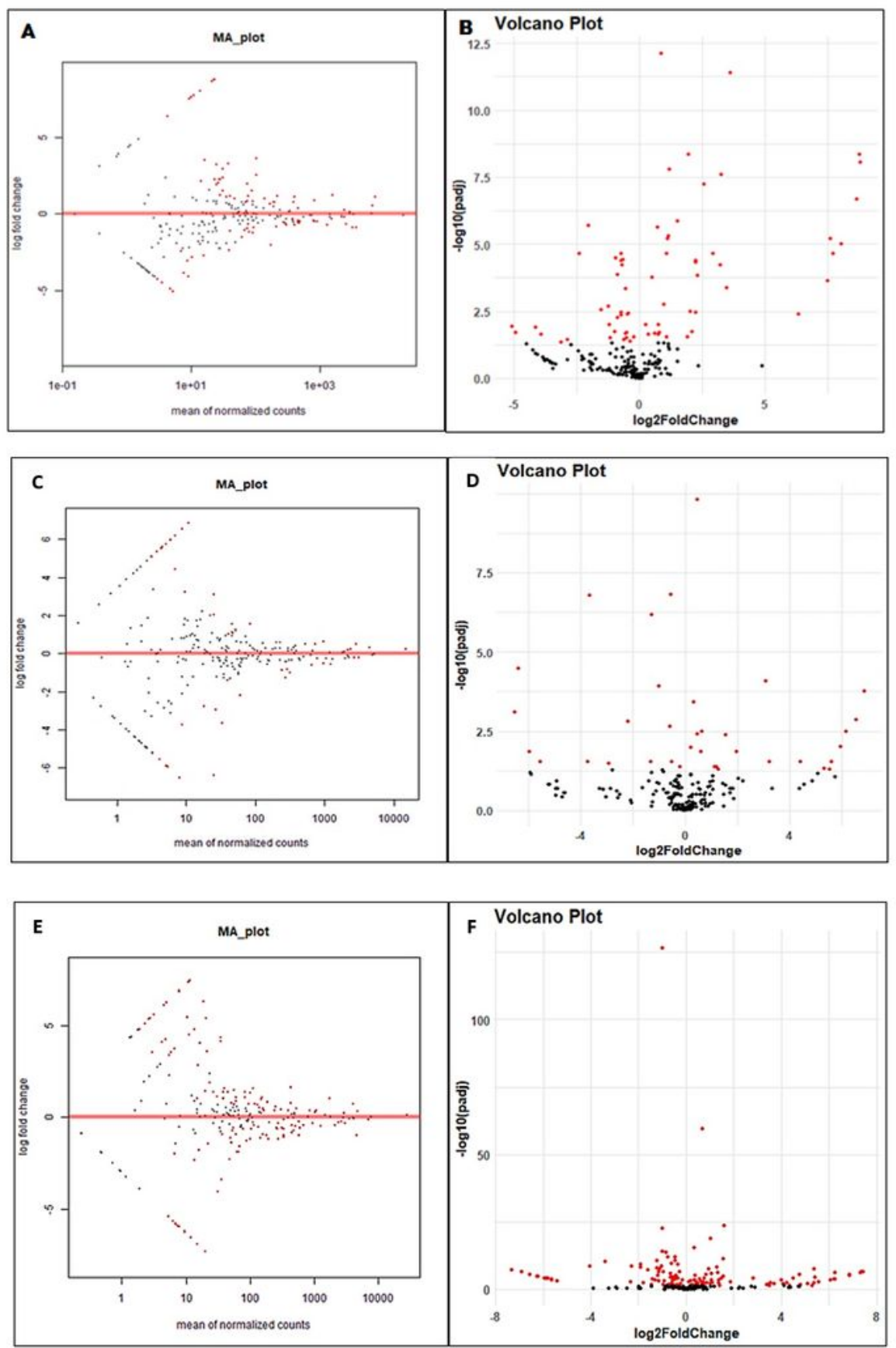

\section{Figure 5}

(A) MA plot depicting the expression pattern of up- and down-regulated miRNAs in cloned relative to IVF embryos at the 2-cell stage. The $\mathrm{Y}$-axis represents the log fold ratio $(\mathrm{M})$ and the $\mathrm{X}$-axis is the mean average of normalized counts A. Red dots represent differentially expressed miRNAs having adjusted p- 
value above threshold value whereas, black dots represent differentially expressed miRNA having $p$-value below threshold. (B) Volcano plot showing differentially expressed up- and down-regulated miRNAs in cloned realtive to IVF embryos at the 2-cell stage. Red dots indicate miRNAs significantly differentially expressed whereas, black dots indicate miRNAs, the expression of which was non-significant in the two groups. The dots towards the left, right and top sides denote down-regulated, up-regulated and most significantly expressed miRNAs, respectively. (C \& D) MA plot and Volcano plot for 8-cell stage cloned embryos relative to IVF counterparts. (E\& F) MA plot and Volcano plot for blastocyst stage cloned embryos relative to IVF counterparts. 
(A)
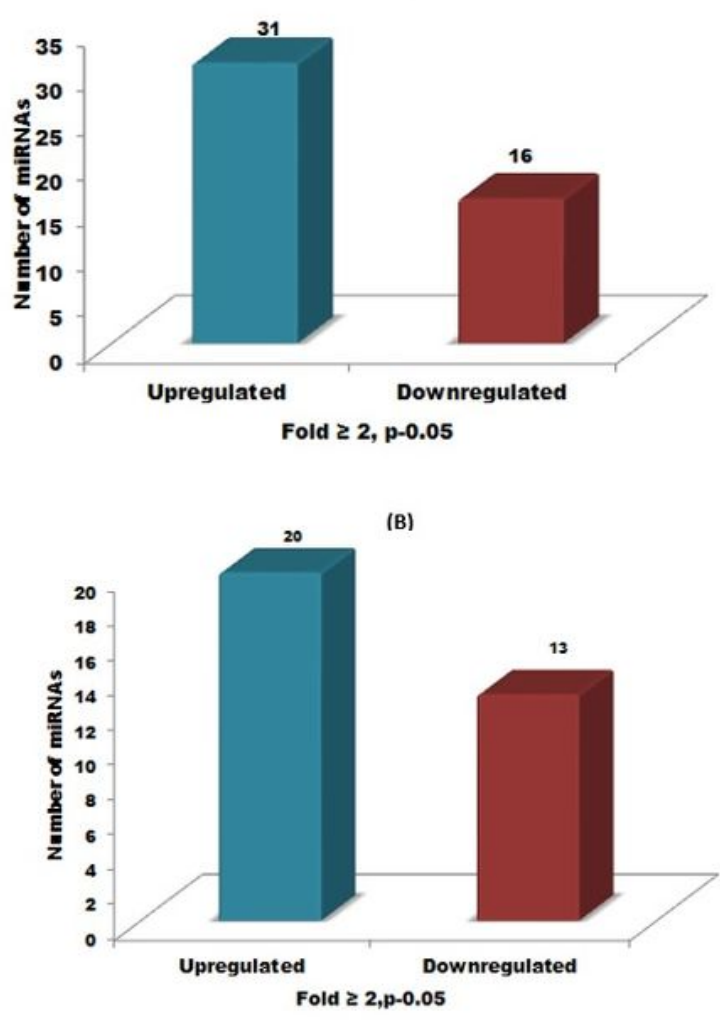

(C)

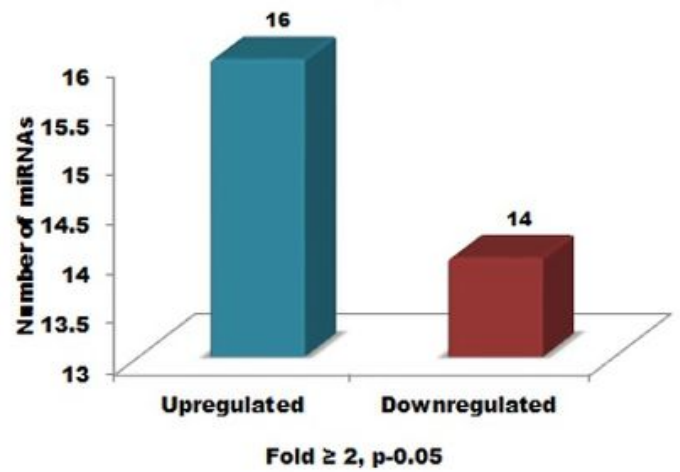

Figure 6

Bar graph depicting the number of differentially expressed miRNAs up- or down- regulated in cloned relative to IVF (A) 2-cell stage (B) 8-cell stage (C) blastocyst stage embryos at $F C \geq 2(p<0.05)$. 
(A)
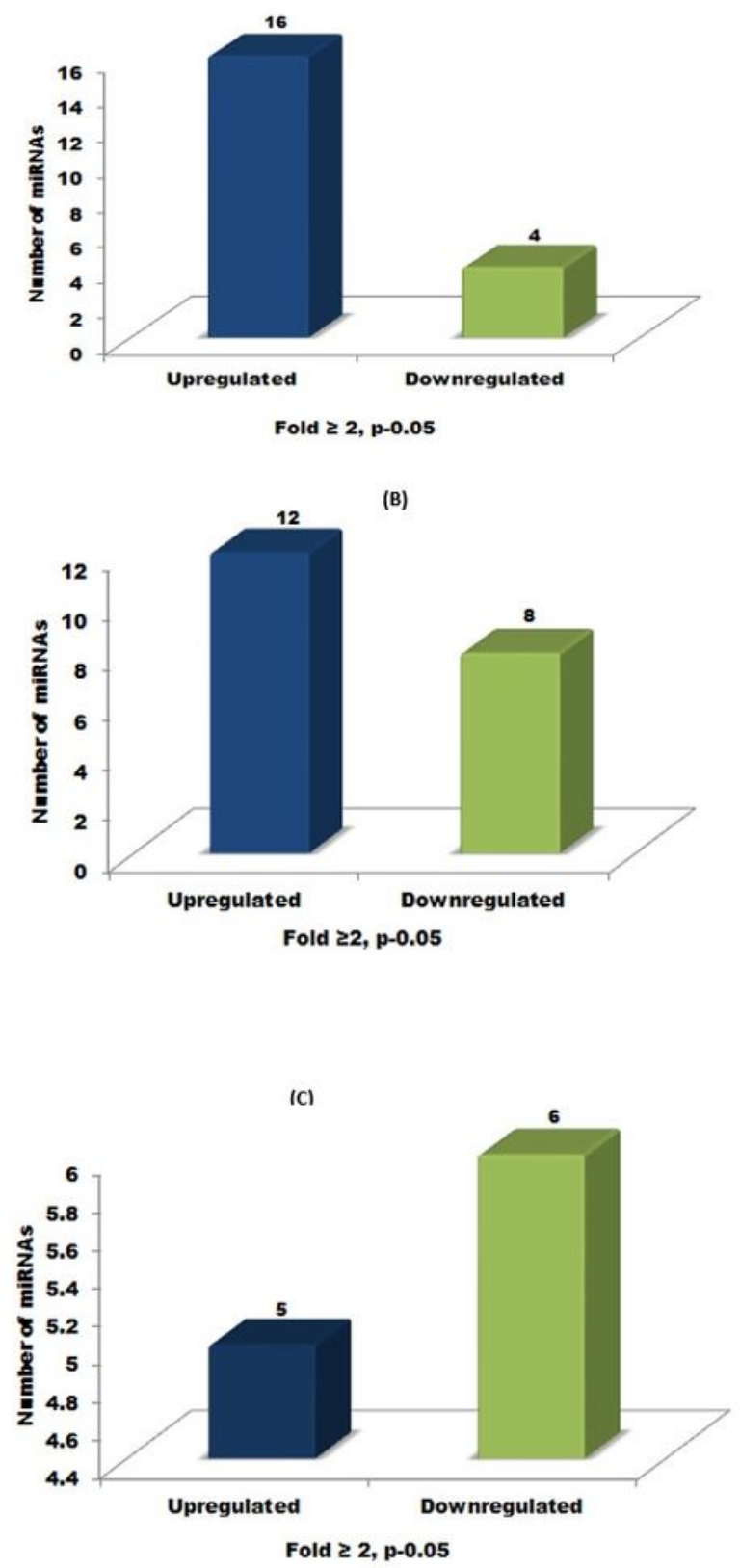

Figure 7

Bar graph depicting the number of commonly expressed miRNAs up- or down- regulated in cloned relative to IVF (A) 2-cell stage (B) 8-cell stage (C) blastocyst stage embryos at FC $\geq 2(p<0.05)$. 


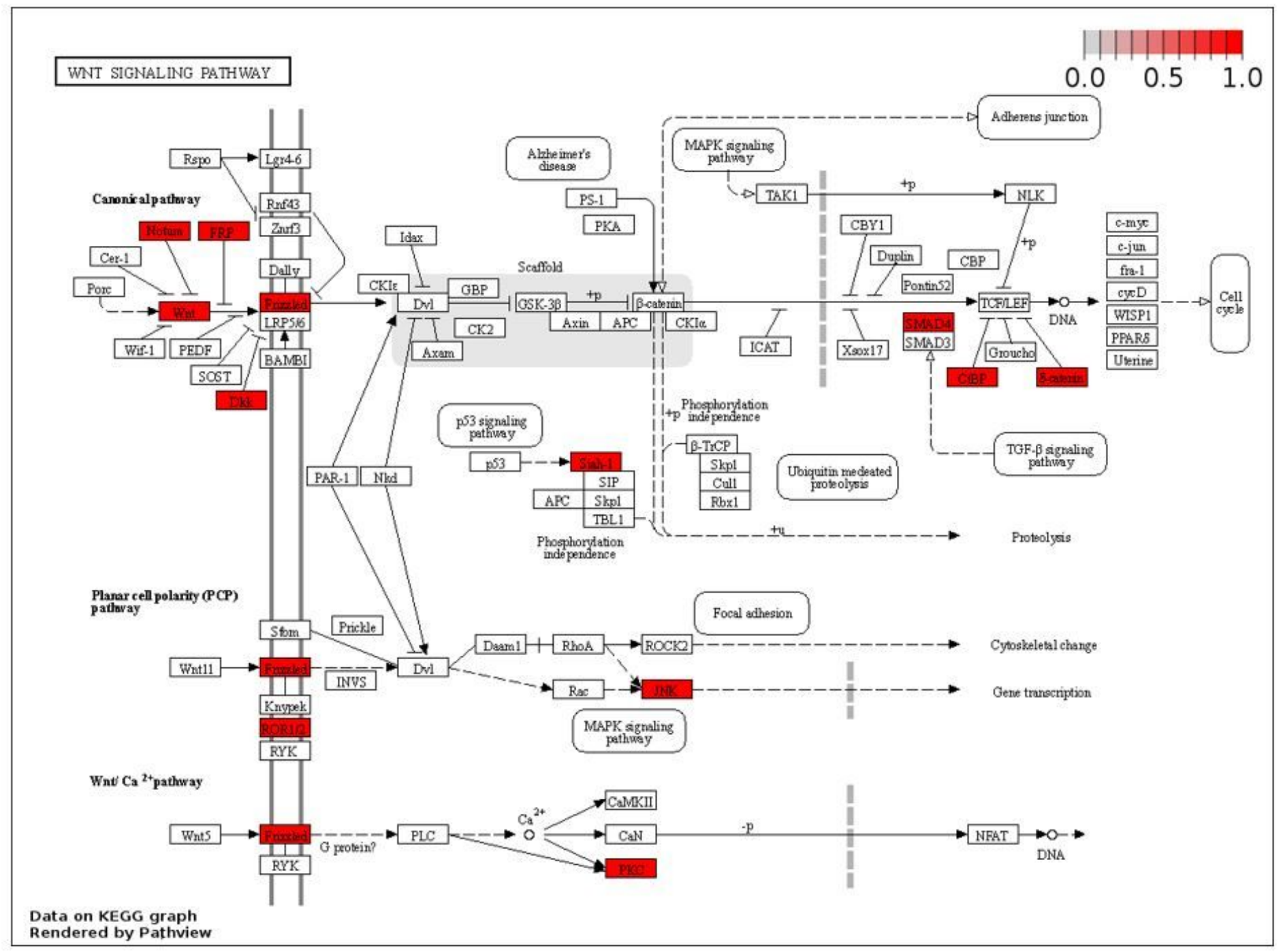

\section{Figure 8}

KEGG reference (bta04310) showing the wnt signaling pathway and target genes affected by under and over presented miRNAs in cloned embryos relative to IVF. 
miR-218

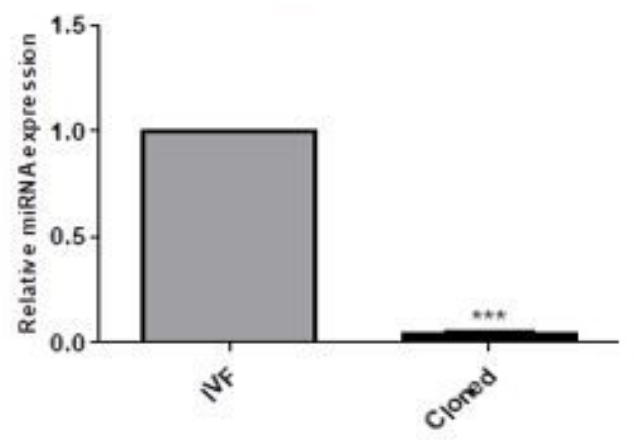

$\operatorname{miR} \mathbf{3 4 0}$
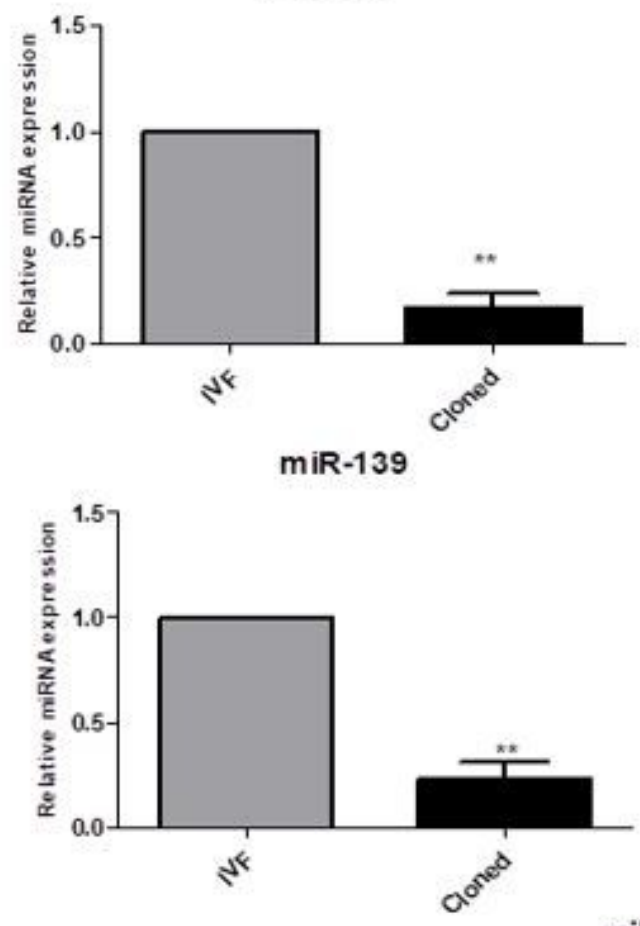

miR-370
miR-202

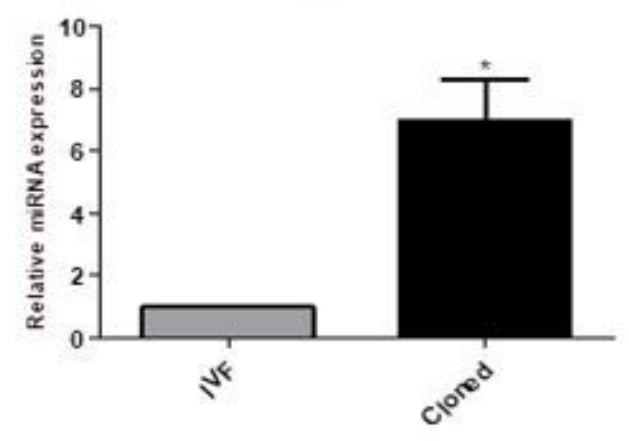

miR-214

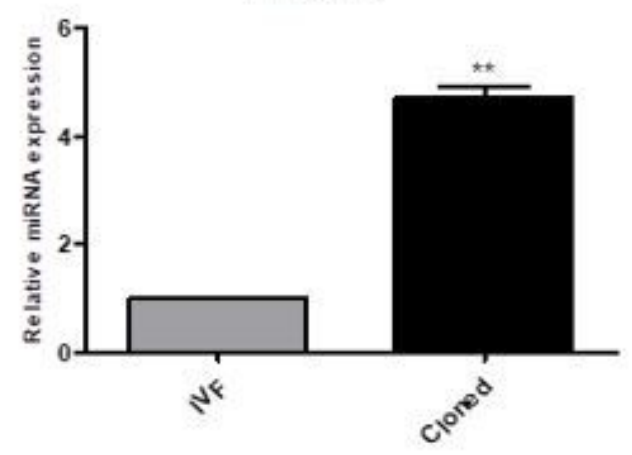

miR-96

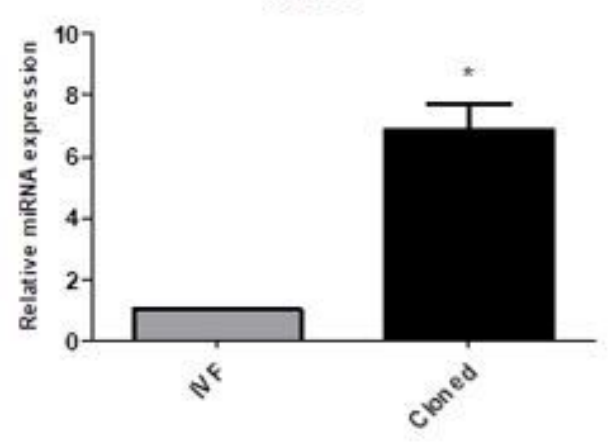

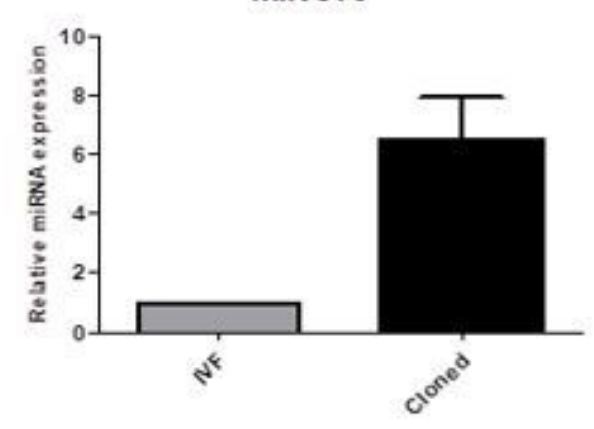

Figure 9

Validation of RNA-seq data by qPCR analysis of 7 miRNAs expressed differentially in cloned and IVF 2cell, 8-cell and blastocyst stage embryos. The pattern and magnitude of relative expression level were found to be similar in RNA-seq and qPCR data. Bars with different superscript differ significantly $\left({ }^{\star} P<0.05 ; * \star P<0.01 ; * \star * P<0.0001\right)$, Values are mean \pm SEM. 


\section{Supplementary Files}

This is a list of supplementary files associated with this preprint. Click to download.

- Supplementarydata.docx 